\title{
Kompetence za ekonomsko diplomacijo in mednarodno poslovanje; konvergenca ali divergenca? 1
}

\author{
UDK: 338.2:339.5/.7 \\ Marjan Svetličič \\ Univerza v Ljubljani, Fakulteta za družbene vede \\ marjansvetlicic@siol.net
}

\section{IZVLEČEK}

Članek ugotarlja ali so kompetence, ki jih potrebuje sodobni ekonomski diplomat, podobne ali različne od tistih, ki jih potrebuje mednarodni poslovnež, ter ali so se ekonomski diplomati z obstoječimi kompetencami sposobni soočati z izzivi tekłonsko spreminjajočega se okolja. Priče smo obojestranski konvergenci potrebnih kompetenc; ekonomski diplomati prevzemajo vse več vrlin mednarodnih poslovnežev, ti pa morajo biti vse boljši diplomati. Posebna pozornost je namenjena zvezi med notranjimi in mednarodnimi ekonomskimi odnosi, globalni naravnanosti, vlogi varnosti ter dolgoročnega planiranja ter toleranci do napak. Ugotavlja se, da so kompetence ekonomskih diplomatov malih držav razlikujejo od tistih iz velikih držav in da sta med ključnimi kompetencami radovednost in pripravljenost na spremembe. Da bi zadovoljili potrebe, bi morali tudi spremeniti izobraževanje tako ekonomskih diplomatov kot mednarodnih poslovnežev.

Ključne besede: ekonomska diplomacija, mednarodno poslovanje, kompetence, mehka znanja

JEL: Al 1, D03, F21, F59, H77, M16

\section{Uvod}

Beremo: Angela Merkel odpira vrata nemškim podjetjem na Kitajskem. Kitajski predsednik svoje poti po svetu uravnava predvsem

1 Članek je del raziskave "Kako izboljšati učinkovitost slovenske gospodarske diplomacije", ki jo financira ARRS (V5-1039) in sofinancira Ministrstvo za zunanje zadeve RS.

Svetličič, M. (201 1). Kompetence za ekonomsko diplomacijo

in mednarodno poslovanje; konvergenca ali divergenca?

Uprava, IX(1), 123-144. 
sledeč ekonomskim interesom. Slovenski predsednik in premier v zadnjem času načrtujeta svoje obiske skladno z ekonomskimi interesi slovenskega gospodarstva. Meddržavne obiske spremljajo močne gospodarske delegacije, vse bolj $v$ tiste države, ki smo nanje po osamosvojitvi popolnoma pozabili. Omeniti neuvrščene ali arabske države, v katerih so imela naša podjetja velik ugled, je bilo skoraj tako, kot če bi omenili komunizem. Škoda, kajti velja, da je ponovno osvajanje trgov zelo drago in da bi moral biti osnovni aksiom gospodarske politike poskusiti zadržati vsak trg, četudi je trenutno mani zanimiv, samo zato, da ne bi kasneje preplačeval vstopnine, če že imaš "abonmajsko" ceno iz poprejšnjih obdobij. Odkrivamo, da (politične) emocije stanejo.

Ekonomska diplomacija (ED) ${ }^{2}$ postaja vse pomembnejša. Zakaj poprejšnji nasprotniki vmešavanja politike $v$ gospodarstvo postajajo keynezijanci? Je vzrok temu kriza ali pa gre za kaj več? Kriza je gotovo naplavila cel niz novih problemov in hkrati državo kot niihovo rešiteliico. Toda ni le kriza tisto, ki je vrnilo državo na ekonomski parket. To so tudi tektonske spremembe $v$ svetu, ko se centri gospodarske moči selijo na Vzhod (več v Svetličič \& Sicherl, 2006). S tem oddaljenejši, mani poznani trgi postajajo osrednji. In podjetja, zlasti manjša, potrebujejo pomoč države $v$ odkrivanju, spoznavanju in prodiranju na te trge. Vse to pa je mogoče uspešno le, če i) država s svojo politiko pravočasno spozna pomen teh trgov in tektonskih sprememb ter če ii) so podjetja s svojimi kadri sposobna prodreti na te trge. Ker gre za drugačne trge, oddaljenejše, tako fizično kot kulturno, so potrebne drugačne kompetence kot za sodelovanje s svojimi "starimi" znanci na bližnjih trgih.

Problem, ki ga želi ta članek poskusiti razrešiti, je ali ED razpolaga z ustreznimi kompetencami za soočanje z novimi izzivi in ali podjetja potrebujejo nova, drugačna znanja za soočanje z novimi izzivi. In drugič ali so te kompetence podobne, so za ED potrebne drugačne kot za mednarodno poslovanje (MP)? Ali gre za konvergenco ali divergenco potrebnih kompetenc in kakšne kompetence omogočajo uspeh $v$ današnjih turbulentnih in nestabilnih pogojih na svetovnem trgu? Poglavje dve opredeli splošni koncept kompetenc, poglavje tri pa primerja

2 ED opredeljujemo kot bilateralno, regionalno ali multilateralno uveljavljanje gospodarskih interesov predvsem od diplomatov, pa tudi od drugih državnih in nedržavnih akterjev s ciljem maksimiranja nacionalnih interesov oz. dvigovanja blaginje prebivalcev. $V$ malih državah ni smiselno ločevati različnih ED (na primer ekonomske, gospodarske, poslovne, podjetniške ali v celo intra podjetniške; glej Udovič, 2009, slika 16).

124 Uprava, letnik IX, 1/2011 
kompetence, potrebne za ED in MP. Poglavje štiri je posvečeno izbranim vidikom delovanja ED in menedžerjev, kot so zveza med notranjimi in zunanjimi odnosi, pomen globalne naravnanosti, pomen analize tvegani in tolerance do napak ter posebnosti malih držav. Peto poglavje analizira konvergenco kompetenc, šesto pa posebnosti malih držav. Zaključek povzame poglavitne ugotovitve in daje nekaj predlogov za politiko.

\section{O kompetencah}

Kompetence so sposobnosti učinkovito opravljati določene naloge. Perrenoud (1997) razume kompetence posameznika kot aktivacijo, uporabo in povezanost znanja, sposobnosti, motivov, samopodobe in vrednot, ki mu v kompleksnih, raznovrstnih in nepredvidliivih situacijah omogočajo uspešno opravljanje vlog, nalog in reševanje problemov. Vsebujejo tako trdo znanje kot veščine (mehko znanje) in ustrezno motiviranost za njihovo udejanjanje (Weinert, 2001). Trdo znanje se pogosto enači s formalno izobrazbo, sai je to znanje, ki se ga da kodificirati in pridobiti $v$ šoli. Mehka pa so tista relacijska ${ }^{3}$ neoprijemljiva znanja, ki jih je težko kvantificirati, kodificirati in skladiščiti ter prenašati, saj se nanašajo bolj na osebnostne značilnosti ali poteze ter vključujejo presoje in izkušnje. Skrivajo se npr. v odgovorih na vprašanja, kako in s kom se je treba dogovarjati, kako strokovno znanje izražati ter p(r)odati na enostaven in razumljiv način. Vedeti kako se nanaša na sposobnost izvajanja določenih nalog, vedeti kdo pa na to, kdo ima znanja o "kaj in zakaj" (trda znanja). Mehka znanja so osebna, skrita (tacitna), neformalizirana znanja, ponotranjene veščine, $k i$ se jih pridobi $z$ izkušnjami in z vajo. Izkušnje pa nekaj pomenijo le, če se udejanjajo na ustrezni strokovni podlagi. Veščine se nanašajo na procedure, spretnosti in inkulturirano znanje, vezano na kontekst (povzeto po Svetličič \& Kajnč, 2009).

\section{Splošna primerjava kompetenc ekonomske diplomacije in mednarodnega poslovanja}

Teoretično je mogoče ED primerjati z odnosi znotraj transnacionalnih podjetii (TP ${ }^{4}$. Pri nijh gre za odnos med centralo in afiliacijami v tujini, pri

3 Ta so pogojena z določenim okoljem in določeno situacijo ter postajajo $v$ negotovem okolju vse boli pomembna.

4 Pri tem sledimo M. Casson-u, ki razvija splošno teorijo internalizacije, v kateri uporabi poslovno teorijo internalizacije na primeru držav, ki so lahko analogija firmi. Ko gre za 
ED pa praviloma za odnos med ministrstvom za zunanje zadeve, vlado, oz. drugimi ministrstvi in ekonomskim diplomatom (več v Svetličič, 2011). Čeprav so tudi odnosi znotraj mreže TP zapleteni, so ti med ekonomskim diplomatom in njegovo centralo še zapletenejši. Ekonomski diplomat pogosto nima tako jasnih navodil kot afiliacije. Niegovih delodajalcev je več, s pogosto nejasnimi in tudi nasprotujočimi se cilji/navodili. Medtem ko se danes organizacija TP spreminja stran od premočne hierarhije $k$ decentralizaciji (mrežna ali projektna organizacija, $z$ več avtonomije $v$ afiliacijah, z distributivnim vodenjem na osnovi enostavnih in fleksibilnih pravil ${ }^{5}$ ), je državna uprava še vedno zelo hierarhično organizirana, funkcionalno ali regionalno oddelčno organizirana. To duši tako potrebno iniciativnost in nujno fleksibilnost ekonomskih diplomatov. Čeprav je diplomacija bistveno starejša dejavnost kot MP, pa je slednje bolj dinamično in se hitreje odziva na spremenjeno zunanje okolje. Zato bi bila močnejša konvergenca tudi pri organizaciji zelo zaželena, saj se ED lahko marsikaj nauči iz organizacije in delovanja TP (povzeto po Svetličič, 2011 ).

Že ta primerjava navaja na ugotovitev, da so določene kompetence $v$ obeh primerih lahko podobne, da pa so gotovo tudi pomembne razlike, tako ko gre za trda kot mehka ${ }^{6}$ znanja/kompetence. Trdo znanje je potrebno ne pa zadostno za uspešno izvajanje nalog in enih in drugih. Pri ED pridobivajo pomen mehka znanja, sai naj bi ekonomski diplomati delovali bolj na področju vedeti kako in kdo, oziroma vključuje presoje, ki pa so lažje na temelju bogatih izkušenj. Uspešneje jih uveljavljajo ljudje s karizmo, ki znajo prepričati, ki imajo mehko moč7. Fukujama (2008) celo govori o tem, da svet danes vodijo šibke države, ker običajni instrumenti moči (kot je vojaška moč) ne delujejo prav dobro. Za takšen novi svet

imperialno državo s kolonijami, je pa to analogno TP, saj ima donose s svojimi kolonijami tako kot centrala TP s svojimi afiliacijami (glej Casson et al., 2006).

5 Glej Nohria, 2006, str. 23.

6 To so: komunikacijske in pogajalske spretnosti, sposobnost mreženja, lobiranja, znanje jezikov medkulturnega komuniciranja in ter seveda uporaba in hitrost udejanjanja znanja. $\mathrm{Na}$ vse to $v$ veliki meri vplivajo tudi prevladujoče vrednote $v$ družbi (Svetličič \& Kajnč, 2009).

7 Nye (2003) "sposobnost vplivanja na vedenje drugih, da dobimo rezultate, ki jih želimo," opredeljuje kot mehko moč.

126 Uprava, letnik IX, 1/2011 
je potreben nov nabor veščin (Fukujama, 2008, str. 40) hitrega vnaprejšnjega prilagajanja nepredvidliivim spremembam.

Na področju ED raziskovalci zaznavajo brisanje razlik med diplomati in strokovnjaki ter porast menedžerskih nalog, ki jih opravljajo diplomati, še zlasti tisti iz manjših držav. Opravljanje strokovnih in menedžerskih nalog pa zahteva drugačna znanja in s tem tudi drugačno izobraževanje (Jazbec, 2008).

Pri MP imajo mehka znanja drugačno pojavno obliko in težo. Nanašajo se na neoprijemljive vire, kot so tehnologija, informacije, menedžerske, trženjske in podjetniške veščine, organizacijske sisteme, motivacijske strukture (Dunning \& Lundan, 2008, str. 96). Ker gre pri MP za delovanje $v$ medkulturnem okolju, morajo imeti kadri, ki se stem spopadajo, specifične kompetence. Beamish \& Killing (2001, str. 178195) med takšne kompetence uvrščata: sposobnost razvijanja in uporabe strateških veščin, upravljanja sprememb in kulturnih raznolikosti, delovanje $\vee$ fleksibilni organizacijskih strukturah in timih, sposobnost odprtega komuniciranja ter učenja in prenosa znanja $v$ organizaciji. Zlasti pomembne kompetence so mednarodna usmerienost, mednarodne marketinške sposobnosti, mednarodna inovativnost in mednarodna trženjska usmeritev (glej Knight \& Kim, 2009). Raziskave, ki se nanašajo na vodstvene kadre $v$ podjetjih, kažejo, da imajo vodilni najšibkejše kompetence prav na področju medkulturne občutljivosti, uvajanja sprememb in voditeljstva. Zato tudi ne preseneča, da je večji problem od samega začrtovanja strategii, kako njihove cilje udejanjati (Hrebiniak, 2005), in prav to je naloga tako menedžerjev kot ekonomskih diplomatov.

Fragmentirana, integrirana mednarodna proizvodnja, največ $v$ režiji TP nalaga nove izzive. Tudi ekonomski diplomati se morajo zavedati teh sprememb in $v$ svojem delu večjo težo dajati zahtevnejšim oblikam mednarodnega poslovanja, saj sodobne komunikacije omogočajo hitre in lahko dostopne informacije o tradicionalnih oblikah MP. Manjka pa ocena zanesliivosti teh, sicer dostopnih informacii, niihove kakovosti. In to je naloga ekonomskih diplomatov. Pri slednjih tradicionalni marketing izgublja pomen, pridobivajo pa drugi načini uveljavljanja vmesnih proizvodov brez blagovnih znamk. Med mednarodnimi poslovneži ter ekonomskimi diplomati obstoja niz podobnosti, ampak tudi razlik (tabela 1). 
Kompetence za ekonomsko diplomacijo in mednarodno poslovanje; konvergenca ali divergenca?

Tabela 1: Primerjava med nalogami menedžerjev in ekonomskih diplomatov

\begin{tabular}{|c|c|}
\hline Naloge menedžerjev & Naloge ekonomskih diplomatov \\
\hline dobri rezultati & $\begin{array}{l}\text { zadovoljiti stranke (vse boli podjetja), doseganje } \\
\text { ciljev }\end{array}$ \\
\hline sodelovanje & $\begin{array}{l}\text { znotraj ministrstva(tev), s podjetji, z inštituti, doseči } \\
\text { povratni tok informacij iz prestolnice }\end{array}$ \\
\hline določanje prioritet & $\begin{array}{l}\text { ne le kot jih določajo nalogodajalci ampak vse } \\
\text { boli samoiniciativno glede na mesto službovanja }\end{array}$ \\
\hline upravljanje & $\begin{array}{l}\text { upravljati celotno raznovrstno mrežo } \\
\text { nalogodajalcev in strank, potreba po manjši } \\
\text { hierarhiji od običajne v upravi }\end{array}$ \\
\hline izvrševanje & $\begin{array}{l}\text { učinkovitost (glede na sredstva) in uspešnost } \\
\text { (efektivnost) glede na cilje, metode }\end{array}$ \\
\hline timsko delo in razvoj kadrov & $\begin{array}{l}\text { stalno prenašati svoja znanja } v \text { prestolnico in } \\
\text { drugim sodelavcem ter strankam }\end{array}$ \\
\hline razreševanje konfliktov & med javnimi in privatnimi interesi ter znotraj njih \\
\hline zaupanje in odgovornost & vzpostaviti večje zaupanje v pomen ED \\
\hline
\end{tabular}

Vir: lastna tabela in Praček, 2010.

$\checkmark$ obeh primerih gre za zadovoljevanje strank in potrebo po učinkovitem sodelovanju za doseganje ciljev. Vendar so naloge ekonomskih diplomatov celo zapletenejše, saj morajo usklajevati med različnimi interesi/ustanovami/strankami in biti boli samoiniciativni.

Spremenjene razmere $\vee$ globalni ekonomiji s fantastičnimi možnostmi dostopa do različnih informacij in znanj terjajo ne le različne funkcije ED pač pa tudi različna znanja/kompetence. Trda znanja so vse bolj dostopna širokemu krogu. Predvsem je pomembno znati oceniti pomen in zanesliivost informacije in kako do nje priti čim prej, po možnosti pred drugimi, in jo še hitreje sporočiti dalje. Gre za ozadje informacije (kdo, zakaj, kako, kdaj) ker tako se omogoči njihovim uporabnikom, da izkoristijo priložnost ${ }^{8}$, ki se pojavi na trgu. Dosedanje napake ED so bile posredovanje sicer dostopnih podatkov na internetu, pa še to

8 Porter (1990) v svojem diamantu konkurenčnih prednosti poudarja dva dejavnika, ki sta $\checkmark$ tem kontekstu pomembna. Prvič vlado, ki pomembno vpliva na konkurenčne prednosti in (ED je sestavni del redne dejavnosti vlad) ter priložnosti. Le-te lahko en ekonomski diplomat najde, drugi pa ne in tako omogoči ali onemogoči izkoristiti poslovno priložnost. Hitrost postaja ključ uspeha zato tudi pri ED. 


\section{Marjan Svetličič \\ Kompetence za ekonomsko diplomacijo in mednarodno \\ poslovanje; konvergenca ali divergenca?}

z velikanskim zamikom namesto, da bi se ukvarjali z interpretacijo pomena teh informacij za konkretne situacije. Nujen je premik od posredovanja informacii $k$ njihovi evalvaciji ${ }^{9}$ vrednosti, realnosti in možnih posledic in predvsem zagotoviti njihovo pravočasno posredovanje. ${ }^{10}$

Mehka znanja, ki naredijo razliko med ljudmi, ki znajo, in tistimi, ki znajo znanje uporabiti in uveljaviti, ki so sposobni uspešne artikulacije svojih znani, postajajo pomembnejša. Churchill je že zdavnaj zatrdil, da ni pomembno, koliko znaš, temveč kako znaš to izraziti. Kar 40 \% angleških delojemalcev je $\vee$ anketi na primer zatrdilo, da najbolj cenijo komunikacijske spretnosti, 39\% delovno etiko, 32\% osebnostne značilnosti, medtem ko so formalni pismenosti pripisali le $26 \%$, računanju $22 \%$ in formalni izobrazbi $25 \%$ (glej Svetličič 2007, str. 233). Vse to ne pomeni nič, če ne znaš tujih jezikov in nisi sposoben uspešne medkulturne komunikacije. $V$ času globalizacije poslovanja in vseh drugih čezmejnih stikov je to znanje neposredna konkurenčna prednost, posebno v stikih $\mathrm{s}$ kulturami, ki veliko dajo na svojo identiteto. Vsaj skromno znanje jezika domačinov je pogosto lahko vstopnica za poslovanje ali vsaj zelo učinkovit katalizator le-tega in s tem krepitve konkurenčnih prednosti.

Tradicionalne kompetence ne zagotavljajo spopadanja z novimi postkriznimi izzivi ${ }^{11}$ selitve razvojnih impulzov $\vee$ Azijo, medkulturnega poslovanja, triangularne diplomacije (države in transnacionalna podjetja), vse večje vloge mednarodnih in nevladnih organizacij do nadzorovanja in urejanja globalizacije, zlasti finančnih pretokov in soočanje z novimi problemi klimatskih sprememb, pomanjkanja vode, energije in surovin

9 Ekonomski diplomat bi moral biti sposoben pravočasno opozoriti ustrezna ministrstva, združenja in podjetja na primer o tem, da je na zasedanju WTO bil sprejet sklep, da bo mednarodni tekstilni sporazum prenehal veljati čez 10 let ali da je prišlo kasneje do podaljšanja tega roka. Na ta način bi se poskušalo pomagati podjetjem, da bi se na to ustrezno in pravočasno pripravila, ne pa da so to z velikim začudenjem "odkrila" šele mesec dni preden je prišlo do tega. Da ne bo pomote, to se ne nanaša le na slovenska podjetja pač pa za večino evropskih, saj je $\vee$ Evropi takrat zavladala panika $\vee$ bojazni, da bo poplava Kitajskega tekstila uničila evropsko tekstilno industrijo. Podobno velja za priprave ustreznih direktiv $\vee$ EU ali četudi neobveznih standardov $\vee$ OECD ali drugih mednarodnih organizacijah.

10 Justinekova raziskava je pokazala, da so bila slovenska podjetja najbolj nezadovoljna s hitrostjo odziva ekonomskih diplomatov in kakovostjo posredovanih informacij. Niegov eksperiment pa da mnoga povpraševanja podjetii ostanejo brez odgovora (Justinek, 2010, str. 7 in 144-148).

$11 \mathrm{Na}$ primer obvladovanje tveganj, sposobnost napovedovanja ... (glej več v Svetličič, $2011)$. 
itd. ${ }^{12}$ Analiza slovenskega predsedovanja Svetu EU je jasno pokazala, da so bile najboli deficitarne prav mehke veščine (še najboli znanje angleščine, zatem retorika, sklepanje poznanstev pa tudi timsko delo). (glej Svetličič in Kajnč, 2009).

Primerjava med zasebnimi in javnimi organizacijami je pokazala, da morajo biti javni uslužbenci bolj vešči v vzdrževanju dobrega sodelovanja s politiko obeh držav. To velja tudi za ekonomske diplomate, saj je njihova naloga ne le ex post obveščati domovino in relevantne akterje $v$ njej o sprejetih novih zakonih in drugih ukrepih, ki jih sprejmejo lokalne vlade, pač pa to storiti še v fazi priprave takšnih zakonov/ukrepov. To pa je mogoče le z vzdrževanjem dobrih formalnih in neformalnih stikov z lokalnimi akterji in je lažje tistim, ki so vešči tudi neformalnega komuniciranja.

\section{Primerjava kompetenc po posameznih vidikih}

Splošna primeriava podobnosti in razlik med ED in MP tudi izhajajoč iz podobnosti in razlik med javnimi in zasebnim sektorjem (glej Svetličič, 2011) je izpostavila razlike in podobnosti, konvergentne in divergentne tendence zlasti na nasledniih vsebinskih področjih:

a) zveza med notranjimi in zunanjimi ekonomskimi odnosi,

b) globalno mišljenje, globalna naravnanost,

c) tveganja in varnostna kultura,

d) dolgoročno planiranje oz. priprava scenarijev.

\subsection{Zveza med notranjimi in zunanjimi ekonomskimi odnosi}

Prva stična točka med ED in MP je povezanost notranjih in zunanjih (ekonomskih) odnosov. MP je praviloma posledica evolutivnega razvoja podjetja, ki postopno širi svojo dejavnost iz notranjega na zunanje trge. Prav tako je ED zelo odvisna od domače politike in razmer. Prioritete ED določa vladajoča elita. Ekonomski diplomati naj bi bili sicer izbrani po strokovnih kriterijih, toda praktično so vedno prisotni tudi politični kriteriji, tistih, ki jih izbirajo. Tudi primerjava med profitnimi in neprofitnimi organizacijami je jasno pokazala, da je pri neprofitnih mnogo pomembnejša kompetenca vzdrževanje dobrih odnosov s politiko. Torej

12 Največ tujih neposrednih investicij (TNI) se $v$ prihodnjih letih na primer predvideva na področju surovin in bistveno mani na področju predelovalne industrije. 
je zveza med notranjimi in zunanjimi odnosi močnejša kot pa pri MP. Trganje te zveze povzroča probleme. Veliko neskladje med notranjim in zunanjim ovira uspešno ED tako kot MP, če ni organske povezave med rastjo podjetja doma in $v$ tujini. Zato je za ekonomskega diplomata izjemno pomembno razviti dobre odnose ne le z gospodarstvom pač pa tudi s političnimi akterii na obeh straneh meje. Podobno pa je za mednarodnega poslovneža obvladati osnovne diplomatske tehnike, saj se $v$ tujini sooča tudi z uradniki lokalne vlade, sindikati, civilno družbo in mediji.

\subsection{Globalno mišljenje, globalna naravnanost}

Tako gospodarstveniki kot ekonomski diplomati morajo biti, če želijo biti uspešni, globalno naravnani. Morajo razviti globalno mišljenje, ki bo preprečilo, da bi vgrajeni filtri zavračali pomembne informacije, ki prihajajo s sveta, pač pa da spreminjajo svoj mišljenjski vzorec s pomočjo diferenciacije in integracije. Bistveno je kombinirati hitrost in ustrezno reakcijo (glej Gupta \& Govindarajan, 2002, str. 200 in 203). Globalna miselnost je osnovna značilnost in predpostavka uspešnega MP in ED, zlasti v primeru malih držav. Takšna miselnost omogoča odprtost do novih idej in predlogov do iskanja "modrih oceanov" ${ }^{13}$. Pogoj za to je interdisciplinarnost, saj se brez nje ne more razviti globalne miselnosti. Čeprav je potrebna pri obeh poklicih, ima interdisciplinarnost večjo težo, ko gre za ED. Zato mora ekonomski diplomat imeti vedno pred sabo ne le enega trga, pač pa vsaj celo regijo, $v$ kateri je, in vedno izhajati iz položaja morebitnih tekmecev $v$ regiii in globalnem gospodarstvu. $V$ te namene pa mora imeti znanja tako iz makroekonomije in politične analitične sposobnosti kot iz mikroekonomije in komunikacijske veščine, da pride do ustreznih informacij iz teh področii.

Nujnost globalne naravnanosti še bolj velja seveda za mednarodnega poslovneža, saj se je izkazalo, da je konkurenčnost danes zaradi njihove globalne optimizacije dejavnosti boli pogojena z multinacionalnostjo kot pa z lastnino (Bellak, 2004; Castelani \& Zanfei, 2006). Zanjo pa potrebujemo veliko več in drugačnega znanja.

13 Po Kim-u in Mauborgne-ju (2005) so to nove priložnosti na trgu, kjer ni konkurence, v bistvu kreiranja novih tržnih niš, za razliko od tam, kjer konkurenca je ("rdeči oceani"). 
Sedanja kriza je še posebej izpostavila nujnost globalne naravnanosti in to navkljub vse večji sinhronizaciji ekonomskih ciklov med državami/regijami. Države, ki so tesnejše vpete v mednarodne tokove, so bile sicer močneje prizadete, toda tiste, ki so pravočasno zaznale, da se dinamika rasti seli v hitro rastoča gospodarstva, so bolje prebrodila krizo. Prva naloga ekonomskih diplomatov je zato ne le zaznati tektonske spremembe $v$ svetu pač pa na njih proaktivno opozarjati podjetja in jim pomagati premagovati tradicionalno vpetost na bližnje trge. Druga pa, otresti se tradicionalnega dojemanja diplomacije kot "visoko leteče salonske" dejavnosti, ki si ne sme mazati rok s pritlehnimi z gospodarskimi interesi. Z besedami Kuniča (2005, str. 9-14) problem gospodarske diplomacije je tudi $v$ miselnosti diplomatov, ki ekonomijo razumejo kot "nizko politiko", medtem ko sebe razumejo kot del "visoke politike".

\subsection{Tveganja in varnostna kultura}

Čeprav analize tveganj niso nove, se je danes zaradi vse večje nepredvidljivosti in negotovosti globalnega okolja niihov pomen bistveno okrepil. Ne nazadnje tudi zato, ker obstaja močna povezanost med zaupanjem in MEO: močnejše zaupanje, več trgovine in TNI. Zato je ključnega pomena, da ED okrepi informiranje o partnerskih državah in s tem medsebojno zaupanje, ker z boljšim informiranjem nezaupanje pada in s tem padajo ovire za medsebojno sodelovanje (glej Guiso et al., 2005, str. 25). Tudi struktura in relativna teža posameznih tvegani se je spremenila. Tradicionalnim ekonomskim in političnim tveganjem je treba dodati geopolitična, okoliska, družbena in tehnološka tveganja (glej World Economic Forum, 2010). Ekonomski diplomati so dolžni poslovneže opozarjati na takšna tveganja. Tudi zato, ker že bežen pogled na niihove analize pokaže, da so bile pogosto točne, da so dobro predvidele tveganja (glej tabelo 5 v World Economic Forum, 2010).

Internetizacija oz. informatizacija vsega poslovanja izpostavlia ranlijvost sistema (prekinjanje dostopa, sesutja baz, nevarnost dostopa nepoklicanih uporabnikov). The Economist zato upravičeno govori o možni "vojni pete domene" (3. 7. 2010, str. 22-24), sai je digitalna infrastruktura postala "strateški nacionalni vir". Predsednik Obama je navedel podatek, da so ZDA zaradi virtualne vojne izgubila leta 2009 1.000 milijard dolarjev. Zaradi nevarnosti vdora hekerjev ali internetnih teroristov so tako ZDA kot VB vzpostavile leta 2010 posebne enote, ki skrbijo za varnost teh sistemov. V času ko je okoli 140 milijard 
elektronskih sporočil neželenih in je virtualno vohunstvo, po Jim Lewisu (Centre for Strategic Studies, Washington) »postalo največja polomija po izgubi nuklearnih tajnih podatkov«, je to še kako potrebno.

Bolj ko svet postaja ranljiv in nepredvidljiv, bolj ko je pomembno neoprijemljivo, skrito znanje, pomembnejša postaja varnostna kultura. Po eni strani kot obramba lastnih interesov in po drugi strani kot dejavnost proaktivne krepitve konkurenčnih prednosti. $V$ neizprosnem konkurenčnem boju se podjetja/države vse bolj poslužujejo tudi nelegalnih poti pridobivanja informacij/znanja, zato je skrb za varovanje znanja vse pomembnejša in se pridružuje pomenu pridobivanja novega znanja ${ }^{14}$. Ekonomski diplomati bi morali boli sistematično opozarjati poslovneže o teh razsežnostih mednarodnega poslovanja, obenem pa paziti, da sami ne razkrivajo informacij o podjetjih, ki jih ta ne želijo razkriti ${ }^{15}$. Ekonomski diplomat mora torej dobro vedeti, kdaj si prizadevati za objavo česa, da ne bi odkril niš, za katere podjetja želijo, da ostanejo skrite. To pa je mogoče le, če je v stalnih in tesnih stikih s poslovneži.

Zato poslovno obveščevalna dejavnost (zbiranje, organiziranje in uporaba poslovnih informacii), vohunstvo o konkurenci (podatki o tekmecih in trgih in izobraževanje) in industrijsko vohunstvo (zbiranje podatkov o proizvodnji) ter skrbno preverjanje dobrega gospodarja in socialne poizvedbe (o kadrih) ${ }^{16}$ pridobivajo na pomenu. Trg poslovno obveščevalne dejavnosti se ocenjuje na vrednost dveh milijard dolarjev letno (Peruško, 2004, str. 2). Ta vidik je še posebno pomemben v Sloveniii, kjer so "poslovne poizvedbe premalo priznane in vrednotene ter zato podcenjene« (glej Gjerek, 2009, str. 10, ter 120-132).

14 Predsednik Bush je na primer leta 1992 posebej izpostavil pomen gospodarskega področja v kontekstu nacionalne varnosti. Clinton je nato ustanovil Nacionalno Ekonomski svet in uvedel neposredno poročanje CIE tudi finančnemu, gospodarskemu in zunanje ekonomskem področju dela. Ustanovil je Odbor za pospeševanje in koordinacijo trgovine in Podporni center. Njune naloge pri nastopanju na tujih trgih so koordinacija dela med podjetji in obveščevalno skupnostjo.

15 Posebno to velja v primeru skritih zmagovalcev, kajti ena od njihovih značilnosti je, da praviloma ne želijo razkrivati podatkov o svojem vodilnem položaju na trgih, ker ne želijo, da bi konkurenti poznali skrivnost njihovega uspeha (glej Simon, 2010, str. 14).

16 Za razliko od vohunstva gre pri poizvedbah za dejavnosti iskanja, obdelave in difuzije informacij iz javno dostopnih virov in le v manjši meri za tajne operacije (Gjerek, 2009, str. 9). 


\subsection{Dolgoročno planiranje/scenariji}

Tradicionalni načini planiranja postajajo $\vee$ negotovih, turbulentnih časih, polnih diskontinuitet in nihani, preživeti. Ustrezneje je torej pripravljati dolgoročne scenarije in predvideti možne alternativne reakcije $\checkmark$ primeru uresničevanja enega ali drugega. Skratka, potrebna je večja prilagodljivost, ki pa zahteva bistveno več znanja in kompetenc. Zato Bryan in Hoffman predlagata firmam, naj:

- opustijo načrte predvideti prihodnost,

- okrepijo svojo sposobnost menedžerskega prilagajanja procesov in sposobnosti $v$ pogojih negotovosti in opustijo zacementirane koledarje in plane. Lotijo naj se raje permanentnega pregledovanja makroekonomskih kazalnikov $v$ realnem času, okrepijo kontingenčno planiranje in prilagodljivost $v$ opcijah (Bryan \& Hoffman, 2009, str. 3). Menedžerii bi morali ovrednotiti poslovanje ali vsak mesec (43\%) ali vsako četrtletje (35\%) ali celo vsak teden (7 \%) (Dye et al., 2009, str. 6).

Podobno velja tudi za ED, ki bi tudi morala biti fleksibilnejša, morala bi znati predvidevati in stalno kritično ocenjevati svoje strategije ${ }^{17}$. Kunič (2005, str. 9-14) ugotavlia, da so politiki pri aplikaciji potreb gospodarstva prepočasni, sai morajo vsako zadevo uskladiti, medtem ko gospodarstveniki delujejo po načelu hic Rodos, hic salta in običajno nimajo časa za dolgotrajna usklajevanja. Počasnost se je pokazala tudi kot značilna razlika med vodenjem $v$ javnih in neprofitnih organizacijah. Višjo odzivnost pa je mogoče doseči le, če si vnaprej pripravljen tudi na nepredvidliivo. Funkcija scenarija prihodnjega razvoja je prav pripraviti se na različne scenarije, tudi na nezaželen razvoj dogodkov. Zato so potrebne pre mortem analize potencialnih problemov ter odločanje na osnovi intuicije, ne le na osnovi robustnih, ocen/predvidevanj. Ta metoda je s spodbujanjem kreativnega mišljenja, kot metodi pridobivanja več različnih mneni (več $\vee$ Svetličič, 2011) zato primerna tako za poslovneže kot ED. Obojim bi morala pre mortem analiza postati del miselnega vzorca.

17 Več v Svetličič, 2011.

134 Uprava, letnik IX, 1/2011 


\section{Konvergenca kompetenc}

Transformirani MEO in intenzivno vključevanje novih akterjev $v$ mednarodne odnose (MO) zahtevajo nove kompetence tako poslovnežev kot ekonomskih diplomatov, da bi bili sposobni reševati odnose $v$ trikotniku med državami, med državami in podjetji ter med podjetji samimi. Saner in Yiu sta s primeriavo izobrazbe, pomena kompetenc ter potrebnih kompetenc za postmodernega diplomata implicitno ugotovila, da so meje med ED in MP vse bolj zabrisane, da obstaja precejšnja konvergenca med potrebnimi kompetencami za ED in MP (Saner \& Yiu 2003, str. 22). Iz njunega pregleda potrebnih kompetenc jasno izhaja, koliko kompetenc MP je potrebnih za "postmoderno ED".

\section{Tabela 2: Ključne kompetence za ekonomsko diplomacijo}

\begin{tabular}{|c|c|c|c|}
\hline $\begin{array}{l}\text { Poslovna } \\
\text { šola/izobrazba }\end{array}$ & $\begin{array}{l}\text { Izobrazba na } \\
\text { diplomatskih } \\
\text { akademijah }\end{array}$ & $\begin{array}{l}\text { Kompetence } \\
\text { so posebej } \\
\text { primerne za }\end{array}$ & $\begin{array}{l}\text { Kompetence za postmoderno diplomatsko } \\
\text { okolje }\end{array}$ \\
\hline $\begin{array}{l}\text { Splošni } \\
\text { menedžment }\end{array}$ & $\begin{array}{l}\text { Zgodovina } \\
\text { diplomacije }\end{array}$ & $\bullet$ & $\begin{array}{l}\text { - Poznavanje diplomatskih prijemov } \\
\text { - Zmožnost vplivanja na diplomatski proces }\end{array}$ \\
\hline $\begin{array}{l}\text { Strateški } \\
\text { menedžment }\end{array}$ & $\begin{array}{l}\text { Sklepanje } \\
\text { sporazumov }\end{array}$ & $\bullet$ & $\begin{array}{l}\text { - Poznavanje ključnih mednarodnih } \\
\text { poslovno-pravnih standardov } \\
\text { - Možnosti vplivanja na oblikovanje zakonov } \\
\text { pri ključnih mednarodnih organizacijah } \\
\text { (WTO, ILO, UNEP, WIPO, OECD). }\end{array}$ \\
\hline $\begin{array}{l}\text { Menedžersko } \\
\text { računovodstvo }\end{array}$ & $\begin{array}{l}\text { Mednarodno } \\
\text { pravo }\end{array}$ & $\bullet$ & $\begin{array}{l}\text { - Poznavanje delovanja mednarodnega } \\
\text { prava in arbitraže } \\
\text { - Poznavanje učinka 'poročanja podjetii } \\
\text { deležnikom' }\end{array}$ \\
\hline $\begin{array}{l}\text { Finančni } \\
\text { menedžment }\end{array}$ & $\begin{array}{l}\text { Mednarodna } \\
\text { ekonomija }\end{array}$ & $\stackrel{\leftrightarrow \bullet}{\bullet \bullet}$ & $\begin{array}{l}\text { - Poznavanie zgodovine in logike ne- } \\
\text { ameriških teorii in praks } \\
\text { - Poznavanje vpliva mednarodnih finančnih } \\
\text { inštitucii (IMF, WB, Pariški klub, Londonski } \\
\text { klub, US FRB, BIS) }\end{array}$ \\
\hline $\begin{array}{l}\text { Kadrovski } \\
\text { menedžment }\end{array}$ & $\begin{array}{l}\text { Mednarodne in } \\
\text { nadnacionalne } \\
\text { organizacije }\end{array}$ & 中. & $\begin{array}{l}\text { - Poznavanje strukture in procesov odločanja } \\
\text { v nadnacionalnih organizacijah (UN, EU, } \\
\text { NAFTA, ASEAN etc) } \\
\text { - Možnosti vplivanja teh organizacij na } \\
\text { neposredne ali posredne načine }\end{array}$ \\
\hline
\end{tabular}

Se nadaljuje na naslednji strani 


\begin{tabular}{|c|c|c|c|}
\hline Marketing & $\begin{array}{l}\text { Regionalne in } \\
\text { državne študije }\end{array}$ & $\bullet$ & $\begin{array}{l}\text { - Poznavanje medsebojnega vplivanja med } \\
\text { ekonomijo, politiko in kulturo po regijah ali } \\
\text { državah } \\
\text { - Sposobnost proaktivno promovirati } \\
\text { možnosti v regiji za poslovno diplomacijo }\end{array}$ \\
\hline $\begin{array}{l}\text { Mednarodni } \\
\text { menedžment }\end{array}$ & $\begin{array}{l}\text { Teorije } \\
\text { mednarodnih } \\
\text { odnosov in } \\
\text { sodobne } \\
\text { zgodovine }\end{array}$ & $\leftrightarrow \bullet$ & $\begin{array}{l}\text { - Poznavanje procesa odločanja v ključnih } \\
\text { državah (domače ali tuje) } \\
\text { - Sposobnost priprave analize političnega } \\
\text { rizika glede na kliučne deležnike v } \\
\text { investiciijskih projektih }\end{array}$ \\
\hline $\begin{array}{l}\text { Operativni } \\
\text { menedžment }\end{array}$ & $\begin{array}{l}\text { Upravlianje z } \\
\text { delegacijami, } \\
\text { ambasadami in } \\
\text { konzulati }\end{array}$ & $\stackrel{4}{* \bullet}$ & $\begin{array}{l}\text { - Poznavanje mehanizmov kriznega } \\
\text { menedžmenta in ustrezne vloge diplomacije } \\
\text { in /vlade } \\
\text { - Sposobnost intervenirati v imenu podjetja }\end{array}$ \\
\hline $\begin{array}{l}\text { Informacijski } \\
\text { menedžment }\end{array}$ & $\begin{array}{l}\text { Sodelovanje z } \\
\text { mediii }\end{array}$ & $\stackrel{+\infty}{*}$ & $\begin{array}{l}\text { - Obvladovanje javnega nastopanja in } \\
\text { medijev (pomembnih govorov, TV } \\
\text { intervjujev, novinarskih konferenc) } \\
\text { - Upravlianje informacijskega sistema } \\
\text { ekonomske diplomacije, ki podpira } \\
\text { strateško planiranje glede na menedžment } \\
\text { deležnikov }\end{array}$ \\
\hline $\begin{array}{l}\text { Organizacija in } \\
\text { spremembe }\end{array}$ & $\begin{array}{l}\text { Pogajalske } \\
\text { veščine } \\
\text { (bilateralne, } \\
\text { multilateralne in } \\
\text { plurilateralne) }\end{array}$ & 中. & $\begin{array}{l}\text { - Obvladovanje mednarodnih pogajani in } \\
\text { vplivanje na pogajanja (bilateralna, } \\
\text { multilateralna, plurilateralna) }\end{array}$ \\
\hline $\begin{array}{l}\text { Kvantitativne } \\
\text { metode }\end{array}$ & $\begin{array}{l}\text { Diplomatsko } \\
\text { obnašanie, } \\
\text { protokol, } \\
\text { sodobna } \\
\text { zgodovina }\end{array}$ & $\bullet$ & $\begin{array}{l}\text { - Obvladovanje diplomatske prakse in } \\
\text { protokola } \\
\text { - Obvladovanje analitičnih orodii npr. } \\
\text { analize deležnikov, niihovega zadovolistva, } \\
\text { planiranje scenarijev itd. }\end{array}$ \\
\hline
\end{tabular}

Kompetence so posebei primerne za:

* ekonomske in komercialne diplomate

- poslovne diplomate

- transnacionalne nevladne diplomate

Vir: prilagojeno po Saner, Yiu \& Sondergaard (2000)

Vidimo, da so $v$ petih od 21 vrst kompetenc potrebnih za postmoderno diplomacijo (zadnji stolpec $\vee$ tabeli 2) potrebne vse vrste kompetenc. Razen pri eni pa sta potrebni dve vrsti. Najpogosteje se pojavljajo enake kompetence $v$ primerih poslovne in transnacionalne diplomacije $^{18}$. Med 21 vrstami kompetenc je samo 8 takih, ki bi jih lahko

18 Ekonomska in komercialna diplomacija se ukvarja z vprašanji ekonomske politike $v \mathrm{MO}$ in z uveljavljanjem komercialnih interesov svoje države. Poslovna z odnosi znotraj multinacionalnih podjetii in njihovim okoljem, transnacionalna diplomacija pa $\mathrm{s}$ čezmernim lobiranjem, tudi z nevladnimi organizacijami (Saner \& Yiv, 2003).

136 Uprava, letnik IX, 1/2011 
ožje definirali koł specifično diplomatske. Vse druge so boli poslovne. Očitno se potrebne kompetence za ED boli približujejo tistim potrebnim za MP kot obratno. Tako $v$ primeru MP kot ED se je treba osredotočati. Uspeh je odvisen od osredotočanja na ključne konkurenčne prednosti/kompetence države/podjetja. To velja posebej za male države, ki lahko s specializacijo na področja svojih primerjalnih prednosti krepijo svojo uspešnost z delovanjem ED (glej Baillie, 1999). Podjetja pa se morajo $v$ zaostrenih pogojih osredotočati na svoje ključne sposobnosti in tako specializirati na izvajanje tistih nalog, pri katerih so najboljše, boljše od drugih.

Tako ED kot MP vse boli uporabliajo podobne vire informacij le da z drugačnih zornih kotov. Oboji morajo veliko več pozornosti posvečati informacijam o mogočem prihodnjem razvoju, o poslovnih tveganjih (zlasti finančnih), o razvoju konkurence ter medkulturnih razlikah. Pri zadnjih naši poslovneži po lastnih ocenah delajo največ napak. Pri ED je to poznavanje še pomembnejše, saj gre za še občutljivejše odnose $s$ politiko države pri izvajanju funkcije javne diplomacije. Primerjava med profitnimi in neprofitnimi organizacijami je tudi pokazala, da so pri neprofitnih pomembnejše kompetence obvladovanja medkulturnih razlik (glej Praček, 2010).

Pri tem ne smemo pozabiti, da so medkulturne razlike tudi $v$ domačih skupinah in se je treba nanje ustrezno pripravljati in odzivati, saj njihovo nepoznavanje lahko preprečuje prenos znanja $\vee$ medkulturnih skupinah. Vedeti namreč moramo, da je "tuje" znanje sprejeto le, če je "tuja" oseba čustveno sprejeta (sicer so: čudaki, nadležneži, ali celo pomenijo grožnjo). Za uspešno premagovanje medkulturnih razlik je nujno krepiti (uvodne) neformalne stike. Ti so pri ED še pomembnejši kot pri poslovnežih.

Različne uteži, ki jih imajo kompetence za uspešno mednarodno poslovanje ali za uspešno ED, izhajajo iz spremenjene vloge, pogojev in načinov MP ter spremenjene vloge dejavnikov konkurenčnosti. Temu primerno se spreminjajo tudi kriteriji izbora, pri katerih tradicionalni kriteriji, na primer izobrazba, postajajo samo potrebni, ne pa zadostni pogoi za izbor. Pridobivajo pomen kompetence kot so medosebne spretnosti, vodenje timov, sposobnost intelektualnega vodenja, sposobnost spodbujanja drugih, komunikacijske in pogajalske veščine, interdisciplinarna znanja in sposobnost vplivanja ter ne nazadnje izkušnje na različnih kontinentih. 


\section{Posebnosti malih držav}

Za male države ima ED relativno večjo težo kot za velike. Prvič to izhaja iz nujnosti večje vpetosti v mednarodne ekonomske odnose (MEO) malih držav in seveda bistveno intenzivnejše internacionalizacije dejavnosti nijhovih podjetii. Celo diplomati velikih držav si dajejo kot visoko prioriteto pospeševanje ekonomskih stikov ${ }^{19}$. Druga specifičnost je, da se male države pri prodiranju na svetovni trg, ob porastu pomena ekonomii obsega in sinergii ter mednarodnega urejanja MEO, srečujejo po eni strani z mani ovir (liberalizacija mednarodne trgovine) po drugi strani pa z več ovirami (konsolidacija trgov, oligopolizacija svetovnega trga, pravila WTO in drugih $M O$ omejujejo njihove strategije in ekonomske politike). Tretiič pa na večji pomen ED malih držav vpliva sprememba $v$ konfiguraciii pogajalskih moči malih držav in njihovih firm. Po eni strani gre za dostop do proizvodnih dejavnikov, po drugi pa za nadzor nad profiti in rentami, ki izhajajo iz MP. Pogajalska moč držav temelji na nadzoru na teritorijem in delovno silo, podjetja pa razpolagajo $\mathrm{s}$ tehnologiio, kapitalom oziroma imajo do njih boljši dostop (glej Stopford \& Strange, 1991, str. 215). Grosse in Behrman (1992) trdita, da so viri držav/vlad: velikost trga in razpoložljivi proizvodni dejavniki, viri podjetij pa sposobnost kreirati vrednost (torej tehnologija, izdelki, znanje, trg) in zaposlitev.

Glede na majhnost, upoštevaje trde dejavnike moči, imajo tako posledično male države bistveno šibkejšo pogajalsko pozicijo kot velike. Male države se tudi mani uspešno poslužujejo trdih, agresivnejših pogajalskih taktik saj nimajo možnosti takšna trda stališča (grožnje) podpreti z uspešnimi ukrepi. Ti lahko izzovejo tudi povračilne ukrepe močnejših držav. Takšne agresivnejše taktike niso najboli kredibilne, kadar jih uporabijo šibke države, ne le ko gre za mednarodno areno pač pa tudi za notranje politične razmere. Posebno če pred tem ne izkoristijo možnosti poiskati zaveznike in podrobno pojasniti svoja stališča. Argumenti sami po sebi $\vee$ kriznih situacijah niso uspešni, če jih ne spremljajo ustrezna pojasnila, ustrezno prepričevanje. Poleg tega imajo male države šibkejše alternative, ki poleg razpolaganja z viri moči krepi pogajalsko pozicijo (glej Dur \& Gemma, 2010, str. 564, 565). Pomembno moč daje malim

19 Na primer ambasador zelo velike države v eni od tranzicijskih držav mi je že leta 1994 na vprašanje čemu bi dal prednost, če bi imel na izbiro sestanek, ki bi omogočil večji posel svoji firmi ali sestanek na temo bolj splošne politične narave, narave globalnih mednarodnih odnosov, jasno povedal, da bi dal prednost ekonomskim interesom. 
državam sposobnost ustvarjanja koalicii, saj z njimi lahko kompenzirajo siceršnje šibke pogajalske vire ${ }^{20}$. Prav zato je pogajalska moč malih držav pogojena z močjo njihovih firm. Posledično je za njih ED bistveno večjega pomena.

Ne samo večja teža ED, tudi funkcije in področja dela ED malih države se razlikujejo. Diplomati malih držav se morajo več ukvarjati s tem, kar smo imenovali mikro ED, morajo skrbeti tudi za posamezne interese firm. Pri tem se lahko ekonomski diplomati malih držav lahko učijo tudi iz izkušenj "skritih zmagovalcev" (Simon, 2010). Skrivnost njihovega uspeha bi lahko strnili v naslednje značilnosti:

a) osredotočanje, specializacija na svoje ključne prednosti in ozke niše,

b) globalna naravnanost od vsega začetka (podobni so rojenim multinacionalkam),

c) osredotočanje na stranke, uporabnike,

d) hitro odzivanje, izkoriščanje prednosti prvega, fleksibilnost,

e) visok pomen mehkih dejavnikov (kultura/pripadnost podjetju, odnos do zaposlenih, lojalnost),

f) ambiciozni cili biti vodilen na svojem področju,

g) skrivnostnost, delovanje izza medijskih luči,

h) stabilni menedžment, ki se pogosto ne spreminja niti 20 let,

i) razvoj majhnih korakov (tudi pri inovacijah) in ne revolucionaren razvoj.

Podobnost z veliko boli splošnimi usmeritvami, ki jih daje teorija malih držav, je očitna. Tudi ta predlaga osredotočanje na nekaj ključnih prednosti, specializacijo, izogibanje konfliktov, fleksibilnost in hitro reaktivnost (glej Bailie, 1999; Bunse, 2009; Thorhallsson, 2000 in 2006). Thorhallson jasno navaja, da lahko majhne države svojo nemoč bistveno vplivati na odločanje $v$ EU kompenzirajo $z$ dobrimi odnosi z uradniki Komisije.

20 Slovenija je tu zelo šibka, saj je med najmani zaželenimi partnerii za sklepanje koalicij v EU (glej Naurin \& Lindahl, 2008). 


\section{Zaključek}

Zaradi tektonskih sprememb $v$ svetu in vse večje prepletenosti in soodvisnosti mednarodnih odnosov in mednarodnega ekonomskega sodelovanja prihaja do vse večje konvergence potrebnih kompetenc za uspešno mednarodno poslovanje in ekonomsko diplomacijo. Podobno velja tudi za menedžment javnih in zasebnih organizacij. Zdi se da ekonomski diplomati prevzemajo vse več kompetenc, $\mathrm{ki}$ delajo mednarodne poslovneže uspešne. Obenem pa morajo poslovneži v vse zapletenejšem globalnem okolju postajati vse bolj vsestransko izobraženi, vse boli interdisciplinarni in uporabljati vse več mehkih metod, ki so značilne za diplomate. Posebno zaradi vse večjega pomena sodelovanja na novih, azijskih trgih, kjer ni mogoče biti uspešen brez poznavanja medkulturnih razlik. Zato je, vzporedno $s$ porastom pomena neoprijemljivega znanja $v$ družbi znanja, bistveno porastel pomen mehkih veščin, ki vse boli odločilno vplivajo na uspeh diplomatov in poslovnežev.

Navkljub konvergenci kompetenc, potrebnih za uspešno MP in ED, pa vseeno obstajajo razlike. Najprej je tu različna povezanost med notranjimi in mednarodnimi ekonomskimi odnosi. Ta je pri ED bistveno pomembnejša, saj se z multinacionalizacijo poslovanja podjetii pri poslovanju vse bolj briše. Globalni vzorec mišljenja je postal za mednarodne poslovneže vzorec preživetja, medtem ko se ekonomski diplomati tega začenjajo zavedati pozneje, z odpiranjem novih oddaljenejših trgov. Na teh novih trgih potrebujejo poslovneži več pomoči diplomatov, saj se podajajo $v$ neznane vode, $v$ katerih je treba več inovativnosti in fleksibilnosti.

Z naraščajočo nestanovitnostjo mednarodnih odnosov in poslovanja se dviga pomen obvladovanja tveganj in krepitev varnostne kulture. Le-ta je dobila $v$ diplomacij že zdavnaj domovinsko pravico, postaja pa vse pomembnejša tudi pri mednarodnem poslovanju, saj se krepijo tudi nelegalni načini krepitve konkurenčnosti. $Z$ nepredvidljivostjo in nestanovitnostio razmer na globalnih trgih se krepi tudi pomen proaktivnega delovanja, dolgoročnih scenarijev, zato da bi se ekonomski diplomati in mednarodni poslovneži vnaprej pripravili na morebitne spremembe. Eden od načinov takega vnaprejšnjega soočanja so pre mortem analize.

Ekonomska diplomacija malih držav, ki so življenjsko odvisne od mednarodnega sodelovanja, ima svoje posebnosti. Ekonomski diplomati 
morajo obvladati več veščin, saj se ne morejo specializirati kot se lahko v velikih državah. Ne nazadnje se lahko učijo od aktivnosti uspeha skritih zmagovalcev, ki jim s specializacijo, hitro odzivnostjo ter ambicioznimi cilji uspe osvajati in ohranjati vodilni položaj na globalnem trgu $\vee$ izbranih nišah.

Osnovni pogoj za uspešno ekonomsko diplomacijo in mednarodno poslovanje je ustrezno izobraževanje, saj stari načini pridobivanja, predvsem trdega znanja, izgubljajo pomen. Potrebno je boli holistično, interdisciplinarno izobraževanje diplomatov z bogatim naborom mehkih veščin, zlasti o medkulturnih odnosih in pogajanjih in te nove kriterije bi morali upoštevati tudi pri izbiranju kadrov za ekonomsko diplomacijo.

Dr. Marjan Svetličic je profesor na FDV, Univerze v Ljubljani (bil tudi njen dekan) in predstojnik Centra za mednarodne odnose. Leta 2002 imenovan za ambasadoria znanosti R. Slovenije. Je Fellow European Academy of International Business (EIBA, bil nien predsednik in podpredsednik), član Sveta TEPSA (Trans Europaen Policy Studies Association) in FP7 Advisory Group for International Scientific Cooperation. Opravlia funkcijo podpredsednika COST projekta The Emergence of Southern Multinationals. Je član uredniških odborov mnogih mednarodnih revij in konzultant mednarodnih organizacij. Bibliografija obsega preko 300 del, od tega veliko objavljenih v tujini. 


\section{Literatura in viri}

- Baillie, S. (1999). A theory of Small state influence in the European union. Journal of Development and International Cooperation. 1 (3-4), 195-219.

- Beamish, P. W. \& Killing, J. P. (2001). Global Strategic Alliances. V: R. Tung (Ur.): The IEBM Handbook of International Business. Cambridge: Thomson Learning.

- Bellak, C. (2004). How Domestic and Foreign Firms Differ and Why Does it Matter? Journal of Economic Surveys, 18(2), 483-514.

- Bryan, L. \& Hoffman, B. (2009). How managers should approach fragile economy? McKinsey Quarterly, September 2009.

- Bunse, S. (2009). Small States and EU Governance: Leadership through the Council Presidency. Houndmills, Basingstoke, Hampshire, UK: Palgrave Macmillan.

- Casson, M., Dark, K. \& Gulamhunssen, M.A. (2009). Extending Internalization Theory: From the multinational enterprise to a knowledgebased empire. International Business Review, 18(3), 232-256.

- Castelani, D. \& Zanfrei, A. (2006). Multinational Firms, innovation and productivity. Cheltham, UK: Edward Elgar Publishing Limited.

- Dunning, J. \& Lundan, S. M. (2008). Multinational Enterprises And The Global Economy. Second Edition. Cheltenham, UK: Edward Elgar.

- Dur, A. \& Gemma, M. (2010). Bargaining Power and Negotiations Tactics: The Negotiations on the EU's Financial Perspective, 2007-13. Journal of Common Market Studies, 48(3), 557-578.

- Dye, R., Sibony, O. \& Viguerie, S. P. (2009). Pridoblieno 13. 4. 2010 s: https://www.mckinseyquarterly.com/Strategic_planning_Three_tips_for_2009 2340

- Economist (2010). War in the fifth domain. July 3, 22-23.

- Fukujama, F. (2008). "Konec hegemona." [The End of the Hegemon]. Mladina, 30, 4042.

- Gjerek, B. (2009). Taktika in metodika dela gospodarskih poizvedovalcev. Specialistična naloga. Maribor: Univerza v Mariboru.

- Grosse, R. \& Behrman, J. (1992). Theory in International Business. Transnational Corporations, 1

- Gupta, A. K. \& Govindarajan, V. (2002). Cultivating a Global Mindset. The Academy of Management Executive. 


\section{Marjan Svetličič \\ Kompetence za ekonomsko diplomacijo in mednarodno \\ poslovanje; konvergenca ali divergenca?}

- Guiso, L., Sapienza, P. \& Zingales, L. (2004). Cultural Biases and Economic Exchange. Univesity of Sassari \& CEPR. Pridoblieno 9. 9. 2010 s:http://www.cepr.org/meets/wkcn/7/765/papers/Zingales.pdf.

- Hrebiniak, L. G. (2005). Making Strategy Work: Leading Effective Execution and Change. Upper Saddle River: Pearson Education.

- Jazbec, M. (2008). Slovensko predsedovanje EU - postmoderni diplomatski eksperiment. Slovenski politološki dnevi. Portorož.

- Justinek G. (2010). Model ekonomske diplomacije Slovenije. Doktorska disertacija. Maribor: Ekonomsko poslovna fakulteta.

- Kim, W. Chan \& Mauborgne, R. (2009). Blue Ocean Strategy; From Theory to Practice. V: Moore, K \& Hebert, L.: Strategy and Globalization. Sage.

- Knight, G. A. \& Kim, D. (2009). International business competence and the contemporary firm. Journal of International Business Studies, 40(2), 255273.

- Kunič, J. (2005). Velike topove hranimo za velike bitke. V: Šmuc (Ur.): Slovenska gospodarska diplomacija kot vzvod hitrejše gospodarske rasti. Ljubliana: Združenje menedžerjev Slovenije.

- Naurin, D. \& Lindahl, R. (2008). East-North-South: Coalition-Building in the Council before and after Enlargement. V: Naurin, D. \& Wallace, H. (Ed.): Unveiling the Council of the European Union. Games Governments Play in Brussels. Basingstoke: Palgrave Macmillan.

- Nohria, N. (2006). The Organization: Survival of the Adaptive. Harvard Business Review. Pridoblieno 21.11.2010 s http://hbr.org/web/2009/pandemic/survival-of-adaptive.

- Nye, Joseph. (2004). Soft Power the Means for Success in World Politics. Cambridge: M. A. Public Affairs US.

- Perrenoud, P. (1997). Construire des compétences dès l'école. Paris: ESF.

- Porter, M. (1990). The Competitive Advantage of Nations. New York: The Free Press.

- Peruško, I. V. (2006). Trenutno stanje uporabe poslovnih informacij v slovenskih organizacijah s poudarkom na Competitive Intelligence. Pridoblieno 18. 6. 2008, s http://www.planetgv.si/upload/htmlarea/files/Odmevi/905InesVrenkoPerusko.ppt

- Praček, R. (2010). Razlike v vodenju profitnih in neprofitnih organizacij. Magistrsko delo. Ljubljana: Fakulteta za družbene vede. 
- Saner, R. \& Yiu, L. (2003). International Economic Diplomacy: Mutations in Post-modern times. Discussion Paper No. 84. Netherlands Institute of International Relations "Clingendael".

- Saner, R., Yiu, L. \& Sondergaard, M. (2000). "Business Diplomacy Management. Core Competency for Global Companies". Academy of Management Executive.

- Simon, H. (2010). Hidden Champions of the Twenty-First century; Success Strategies of Unknown World Market Leaders. Dordrecht, Heidelberg, London, New York :Springer.

- Stopford, J. \& Strange, S. (1991). Rival states, rival firms: competition for world market shares. Cambridge: Cambridge University Press.

- Svetličič, M. (2007). Izobraževanje in konkurenčnost gospodarstva. V Karmberger, A. \& Pavlin, S. (Ed.): Zaposlijvost v Sloveniji. Ljubliana: Fakulteta za družbene vede.

- Svetličič M. (201 1, v tisku). Diplomacija in mednarodno poslovanje v 21. stoletju: komplementarnost ali nadomestnost. Teorija in praksa.

- Svetličič, M. \& Sicherl, P. (2006): Kitajci prihajajo; grožnja ali priložnost? Izzivi tektonskih sprememb v svetu za razvoj Slovenije. Teorija in praksa, 43(5-6), 690-715.

- Svetličič, M. \& Kajnč, S. (2009): Neformalni viri vpliva v EU: trda in mehka znanja ter učinkovitost slovenske državne uprave v času predsedovanja Svetu EU. Družboslovne razprave, 25(61), 59-79.

- Udovič, B. (2009). Ekonomska diplomacija. Ljubljana: Fakulteta za družbene vede.

- Thorhallsson, B. (2006): The Size of States in the European Union: Theoretical and Conceptual Perspectives. Journal of European Integration, 28(1), 7-31.

- Thorhallsson, B. (2000): The Role of Small States in the European Union. Aldershot, Hampshire: Ashgate.

- Weinert, Franz E. (2001): Concept of Competence. A conceptual clarification. V: Rychen, Dominique S. \& Salganik, Laura H. (Ed.): Defining and Selecting Key Competences. Hogrefe\&Huber Publishers.

- World Economic forum. (2010): Global Risks 2010; A Global Risk Network Report. In collaboration with Citi Marsh \& McLennan Companies (MMC) Swiss Re Wharton School Risk Center Zurich Financial Services, Geneva. pridoblieno 13. 4. $2010, \mathrm{~s}$

http://www.weforum.org/pdf/globalrisk/globalrisks2010v1/landscape.htm.

144 Uprava, letnik IX, 1/2011 